\title{
Tube Thoracostomy: Is an Emergency Physician Adequate for the Job?
}

\author{
Sinem Doğruyol' ${ }^{1}$ Vehbi Özaydın², Halil Tözüm³ ${ }^{3}$, Onur İncealtın², Didem Ay² \\ 'Department of Emergency Medicine, Tunceli Government Hospital, Tunceli, Turkey \\ ${ }^{2}$ Department of Emergency Medicine, Medeniyet University Göztepe Training and Research Hospital, İstanbul, Turkey \\ ${ }^{3}$ Department of Thoracic Surgery, Medeniyet University Göztepe Training and Research Hospital, İstanbul, Turkey
}

Cite this article as: Doğruyol S, Özaydın V, Tözüm H, İncealtın O, Ay D. Tube Thoracostomy: Is an Emergency Physician Adequate for the Job? Eurasian J Emerg Med 2017; 16: 97-101

\begin{abstract}
Aim: The aim of this study was to evaluate patients with spontaneous pneumothorax who were admitted to the Medeniyet University Goztepe Training and Research Hospital and to emphasize that effective treatment can be performed in emergency departments by emergency physicians.

Materials and Methods: Patients who were treated for spontaneous pneumothorax between January 1, 2013 and January 1, 2015 were retrospectively evaluated. Patient records were reviewed for variables, including patient age, sex, body mass index, smoking history, comorbidities, presenting complaints, localization and extent of pneumothorax, treatment method, surgical indications, relapse, morbidity and mortality rates, and duration of hospitalization.
\end{abstract}

Results: In total, 50 spontaneous pneumothorax cases were evaluated in this study (41 males and 9 females), and the mean age was $33.3 \pm 14.9$ years. Of these, $38(76.0 \%)$ were primary and $12(24.0 \%)$ were secondary spontaneous pneumothorax cases. Spontaneous pneumothorax cases were observed more often during the winter months $(46.0 \%)$. The leading presenting symptom of patients with comorbidities was dyspnea (71.4\%), whereas that of patients without comorbidities was chest pain (66.7\%). Complications due to tube thoracostomy occurred in $15.1 \%$ of the patients. The mean duration of hospitalization for patients with spontaneous pneumothorax was $5.0 \pm 2.2$ days.

Conclusion: Spontaneous pneumothorax is a common condition that requires effective treatment in emergency medicine practice. Emergency physicians should be well aware of the significance of this clinical condition and its treatment methods. Tube thoracostomy, with its low complication rate, is a procedure that can be safely performed by emergency physicians in emergency departments in hospitals.

Keywords: Emergency medicine, spontaneous pneumothorax, tube thoracostomy

\section{Introduction}

Spontaneous pneumothorax is a collection of air in the pleural space without any traumatic or iatrogenic factors. If there is no identified underlying lung disease and the lung structure is normal, the condition is defined as primary spontaneous pneumothorax (PSP); if an underlying lung disease such as chronic obstructive lung disease (COPD) or tuberculosis is present, then the condition is called secondary spontaneous pneumothorax (SSP) (1).
Primary spontaneous pneumothorax typically occurs in young, asthenic adults. Males and smokers are at higher risk. The most common cause for SSP is COPD (2). These patients may have a more serious clinical course based on the pre-existing impaired lung function. The aim of this study was to evaluate patients with spontaneous pneumothorax who were admitted to our center and to emphasize that effective treatment can be performed in emergency departments by emergency physicians. 


\section{Materials and Methods}

Patients who were treated in the department of emergency medicine in our center (a tertiary hospital) between January 1, 2013 and January 1, 2015 for spontaneous pneumothorax were retrospectively evaluated. Patients who had trauma history, were treated in our center, and were $<18$ years of age were excluded from the study. The study was approved by Istanbul Medeniyet University Goztepe Research and Training Hospital Ethics Committee. Written informed consent was obtained from the patients who participated in this study. The diagnosis was confirmed by medical history, physical examination, posteroanterior (PA) chest X-ray, and thoracic computerized tomography (CT) in case of doubt. The pneumothorax size was estimated using the Light method (3).

Patient records were reviewed for variables, including patient age, sex, body mass index (BMI), smoking history, comorbidities, presenting complaints, localization and extent of pneumothorax, treatment method, surgical indications, relapse, morbidity and mortality rates and duration of hospitalization. The treatment method was determined, and tube thoracostomy was applied according to the British Thoracic Society and American College of Chest Physicians guidelines $(4,5)$. Patients with $<2 \mathrm{~cm}$ PSP without any symptoms were observed. All the other patients underwent tube thoracostomy. Tube thoracostomy was performed in emergency departments by emergency medicine assistant doctors under the supervision of a senior emergency medicine assistant doctor or an emergency medicine specialist. Complication types and tube thoracostomy procedure rates in the emergency department were evaluated in accordance with the literature. The tube thoracostomy procedure was accepted to be successful in patients who did not need revision for their tubes. After their condition stabilized, patients were transferred to the thoracic surgery clinic.

\section{Statistical analysis}

IBM Statistical Package for the Social Sciences (IBM SPSS Statistics; Armonk, NY, USA) version 21.0 was used to analyze the data acquired in the study. Pearson's chi-square and Fisher's exact tests were used to compare qualitative data. All the results were given within $95 \%$ confidence interval, and the level of significance was determined as $\mathrm{p}<0.05$.

\section{Results}

Among the 50 patients with spontaneous pneumothorax evaluated in the study, 41 were males (82\%) and nine were females (18\%), and the mean age was $33.2 \pm 14.9$ years. The overall rate of smoking was $44.0 \%$, and there was a statistically significant difference for sex; $11.1 \%$ of the female patients and $51.2 \%$ of the male patients were smokers (Table 1).

Among the evaluated patients with spontaneous pneumothorax, $38(76 \%)$ had PSP and $12(24 \%)$ had SSP. Comorbidity was seen in $14(28 \%)$ patients. BMI of the patients was calculated; $3(6 \%)$ patients were underweight, 30 (60\%) were normal, 13 (26\%) were overweight, and $4(8 \%)$ were obese. The average BMI was found as $22.9 \pm 4.6$.

Spontaneous pneumothorax cases were observed more often during the winter months (46\%); $24 \%, 16 \%$, and $14 \%$ cases were observed during the spring, autumn, and summer months, respectively. The leading presenting symptom of patients with comorbidities was
Table 1. Relation between sex and smoking

\begin{tabular}{|c|c|c|c|c|c|c|}
\hline \multicolumn{2}{|c|}{} & \multicolumn{2}{|c|}{ Male } & \multicolumn{2}{c|}{ Female } & \multirow{2}{*}{} \\
\cline { 2 - 6 } \multicolumn{2}{|c|}{} & $\mathbf{n}$ & $\%$ & $\mathbf{n}$ & $\%$ & P \\
\hline \multirow{2}{*}{ Smoking } & Yes & 21 & 51.2 & 1 & 11.1 & \multirow{2}{*}{$\mathrm{X}^{2}=4.818$} \\
\cline { 2 - 6 } & No & 20 & 48.8 & 8 & 88.9 & $\mathrm{p}=0.030$ \\
\hline
\end{tabular}

Table 2. Relation between spontaneous pneumothorax types and symptoms

\begin{tabular}{|l|c|c|c|c|c|c|}
\hline \multicolumn{2}{|c|}{} & \multicolumn{2}{|c|}{ Primary } & \multicolumn{2}{c|}{ Secondary } & \multirow{2}{*}{} \\
\cline { 2 - 6 } \multicolumn{2}{|c|}{} & $\mathbf{n}$ & $\%$ & $\mathbf{n}$ & $\%$ & P \\
\hline \multirow{3}{*}{ Symptom } & None & 1 & 2.6 & 0 & 0.0 & \multirow{2}{*}{$\mathrm{X}^{2}=13.714$} \\
\cline { 2 - 6 } & Chest pain & 21 & 55.3 & 3 & 25.0 & $\mathrm{p}=0.003$ \\
\cline { 2 - 6 } & Dyspnea & 5 & 13.2 & 8 & 66.7 & \\
\cline { 2 - 6 } & $\begin{array}{c}\text { Chest pain } \\
\text { and dyspnea }\end{array}$ & 11 & 28.9 & 1 & 8.3 & \\
\hline
\end{tabular}

dyspnea (71.4\%), whereas that for patients without comorbidities was chest pain (66.7\%). Most of these patients (86.1\%) were considered to have PSP. Both results were statistically significant (Table 2). Pneumothorax was observed in the right lung in $52 \%$ of the cases and in the left lung in $44 \%$ of the cases. A bilateral condition occurred in $4 \%$.

Tube thoracostomy was performed in $33(66 \%)$ patients and 17 (34\%) patients were observedComplications due to tube thoracostomy occurred in $5(15.1 \%)$ patients. Tube detachment and tube malposition was seen in two and two patients, respectively. A revision surgery for tube thoracostomy was performed in these four patients. The tube thoracostomy success rate was $88 \%$. Wound infection and the necessity for intensive care was observed in a single (2\%) patient as morbidity. No mortality was seen in the study group. The overall mean duration of hospitalization $5.0 \pm 2.2$ days and that for patients with spontaneous pneumothorax who had undergone thoracostomy was $4.9 \pm 2.2$ days. The relapse ratio was $12 \%$ after discharge. The operation rate due to spontaneous pneumothorax was $22 \%$, and the most common indication for surgical treatment was prolonged air leak (27\%).

\section{Discussion}

Spontaneous pneumothorax commonly occurs in tall, thin, young male smokers. Smoking is the most common risk factor (6) and is associated with a $12 \%$ risk of developing pneumothorax in smokers (7). A history of smoking was present in $44 \%$ of the patients. Regarding the typical patient profile for spontaneous pneumothorax, the incidence in males is six times higher compared with that in females, which is suggested to be related to smoking (8). Similarly, the majority of the patients with spontaneous pneumothorax in this study were males.

Spontaneous pneumothorax is referred to as PSP if it occurs in otherwise healthy individuals and as SSP if it occurs in individuals with an underlying lung disease (5). PSP typically occurs in thin, tall men aged 12-30 years; it is uncommon after the age of 40 years (1). In accordance with the literature, PSP cases in the study were generally younger than 40 years, and the majority of them were male patients with a low or normal BMI $(\geq 18.5$ and $<25)$. 
Secondary spontaneous pneumothorax develops in association with an underlying lung disease and is seen more often in middle to advanced age groups (9). In our study the mean age of patients with SSP and the sex of patients with pneumothorax were in accordance with the literature (10). According to the literature, COPD is an etiological factor in $40 \%-60 \%$ cases of SSP (11). In this study, COPD was the leading etiological factor in SSP as well.

According to Türker et al. (12) and Gürbüz et al. (13), more cases were observed during the fall and spring months, respectively. On the other hand, Celik et al. (14) found no relation between the occurrence of spontaneous pneumothorax in a particular season or month. Although some of the studies have reported right lung predominance for spontaneous pneumothorax, others found no difference between right and left lungs (15). This study had a minor dominance in the right lung.

The main clinical findings of spontaneous pneumothorax are sudden onset of chest pain, dyspnea, tachycardia, perspiration, hypotension, pallor, and cyanosis (1). The most common symptom in patients with PSP is sudden onset of chest pain and that in patients with SSP is dyspnea. The clinical course in SSP is worse and independent of the extent of pneumothorax $(1,2)$. In this study, the main symptom presented by patients with PSP was chest pain and that by patients with SSP was dyspnea; these results were statistically significant.

Types of complaints, physical examination, and PA chest X-ray are generally sufficient to diagnose spontaneous pneumothorax. CT may be required to differentiate minimal pneumothorax or bullae (16). PA chest X-rays were available for each patient. Thoracic CT was performed in most of the patients to evaluate lung parenchyma and to improve the treatment approach.

The aim of treatment in spontaneous pneumothorax is to remove air from the pleural cavity to allow for re-expansion of the lung and to prevent recurrence. Treatment methods include observation, aspiration, catheter drainage, chest tube drainage, and surgery (17).

The choice of initial management for PSP has remained controversial (18). In a case series published in Turkey, tube thoracostomy stands out as the first treatment choice for all types of pneumothorax (19). Noppen et al. (20) have reported a treatment success rate of $63 \%$ for tube thoracostomy. The retrospective evaluation in this study showed that tube thoracostomy was used more than observation for the treatment of PSP, and simple aspiration was not used.

Secondary spontaneous pneumothorax has a more dramatic clinical course compared with PSP, and success is less likely with simple aspiration (21). Therefore, a more aggressive treatment is recommended although consensus remains limited. Published studies indicate tube thoracostomy may be required in the majority of these patients (22). Data from this study show that tube thoracostomy was performed in all patients with SSP, except for two patients whose condition was stable with their small pneumothoraxes. The success rate of tube thoracostomy was in accordance with the literature (23).

The most common indication for surgery in the first episode of spontaneous pneumothorax is a prolonged air leak (24). Others include insufficient expansion, single large bulla, ipsilateral recurrence, bilateral spontaneous pneumothorax, and occupational risk of the patient. The most common surgical treatment indication in this study was prolonged air leak.

Additionally, this study aimed to evaluate the complications of tube thoracostomy procedure performed in patients with spon-

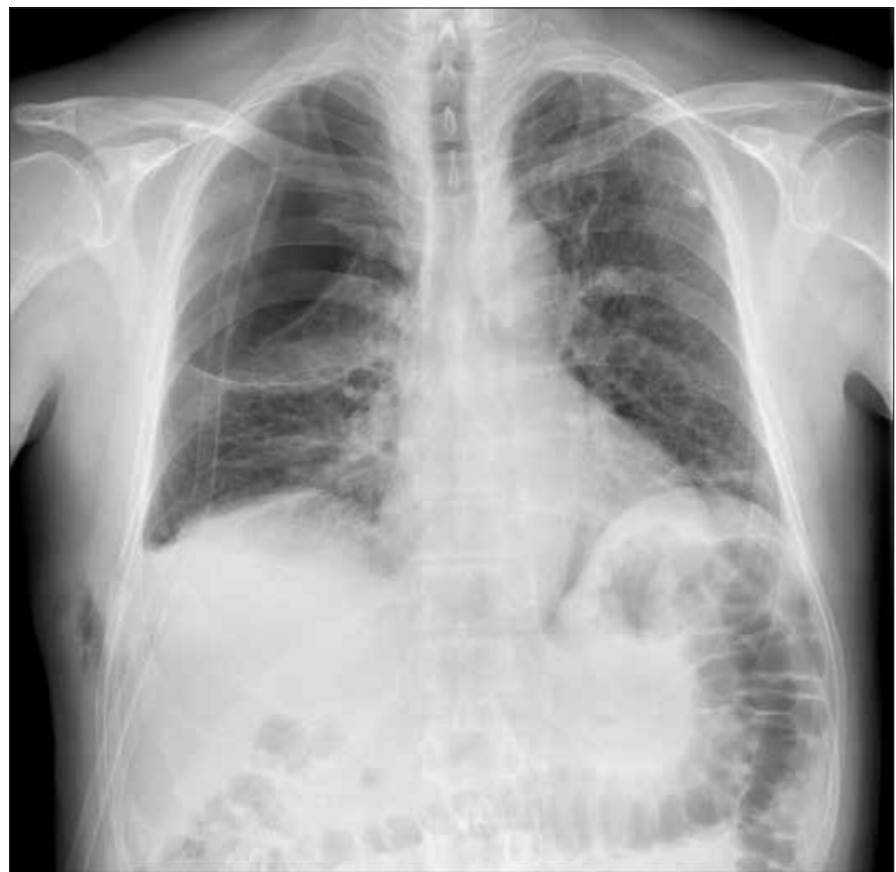

Figure 1. Posterior-anterior lung X-ray of a right spontaneous pneumothorax after tube thoracostomy

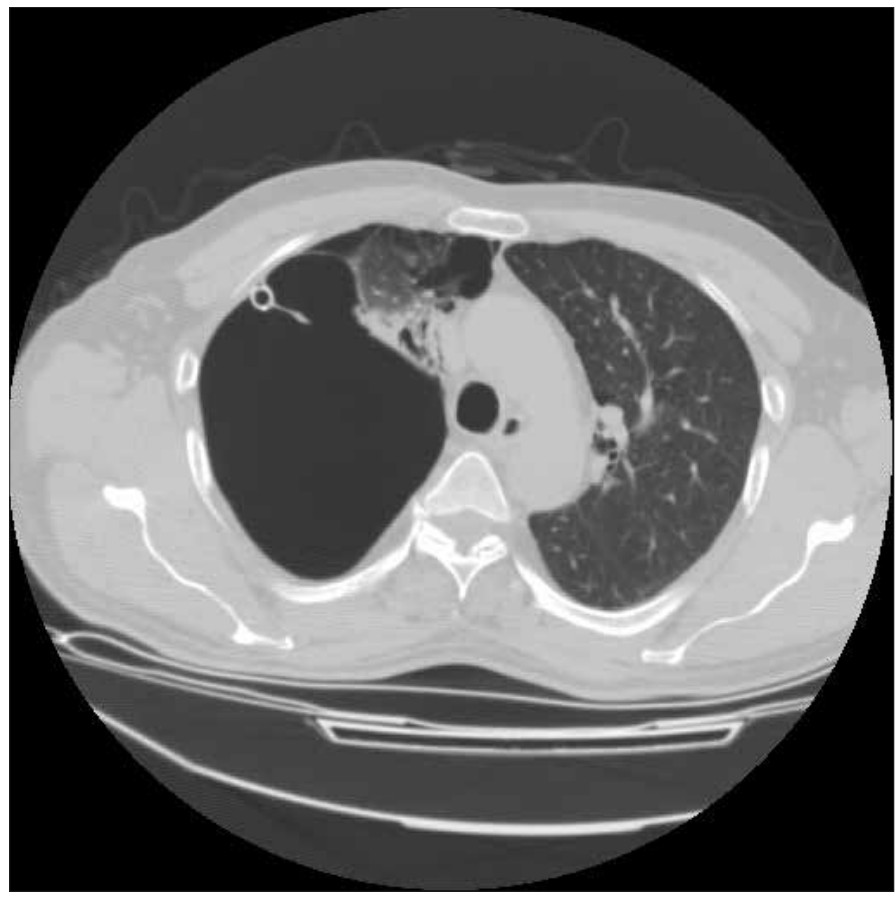

Figure 2. Axial computerized tomography image of a chest drain was inserted in a giant bulla

taneous pneumothorax in the emergency department in relation to the literature. In general, the reported rate of complications of tube thoracostomy ranges between $3 \%$ and $18 \%$ (1). Huber et al. (25) reported an $11.2 \%$ risk of tube malposition. In this study, the most common complication observed was tube malposition. A chest drain was inserted in one patient with a giant bulla (Figures 1 and 2). The study by Aylwin et al. (26) classified complications as major or minor based on their life-threatening potential. 
Although the rate of complications was in accordance with the literature, no major complications were observed in this study group. A recent article found no significant difference between surgical and emergency room residents regarding the quality of tube thoracostomy placement and its subsequent complications in trauma patients (27).

The presence of comorbidities is a major factor contributing to an increased rate of complications in tube thoracostomy procedures. Pulmonary diseases may induce complications by either directly hampering re-expansion or precipitating infections. The risk for a prolonged air leak is higher in patients with advanced emphysema (28). In this study, among the patients who had tube thoracostomy complications, pulmonary changes were observed in all of them on the CT scan.

According to the literature, the recurrence rate is $16 \%-52 \%$, based on the treatment method used for the first episode of spontaneous pneumothorax (29). Studies reporting higher recurrence rate in SSP than in PSP are available, although the reverse is also reported (30). In this study, recurrence was seen in only patients with PSP.

Mortality was not recorded in this study group, except for one patient who was an elderly patient with SSP (aged $>70$ ) with history of malignancy and required intensive care. Risk factors for serious morbidity in pneumothorax are low oxygen saturation at admission, the presence of comorbidities, and SSP $(31,32)$.

\section{Study limitations}

The main limitation of this study was the patient count; larger number of patients may bring out more accurate statistical results.

\section{Conclusion}

Spontaneous pneumothorax is a condition often encountered in emergency medicine practice. Similarly, tube thoracostomy, which is an essential part of emergency treatment of spontaneous pneumothorax, plays an important role in the daily routine of emergency physicians, who generally are the first ones to see these patients. Therefore, emergency physicians should be well aware of the significance of this clinical condition and its treatment methods. Tube thoracostomy is a procedure that can be performed by emergency physicians with a high success rate.

Ethics Committee Approval: Ethics committee approval was received for this study from the ethics committee of Istanbul Medeniyet University Goztepe Research and Training Hospital.

Informed Consent: Written informed consent was obtained from patients who participated in this study.

Conflict of Interest: No conflict of interest was declared by the authors.

Financial Disclosure: The authors declared that this study has received no financial support.

\section{References}

1. Shields TW. The pleura. In Shields TW, LoCicerolll J, Reed CE, Feins RH, ed. General Thoracic Surgery, vol 1, 7th ed. Philadelphia: Lippincott Williams and Wilkins 2009; 740-61.
2. Sahn SA, Heffner JE. Spontaneous pneumothorax. N Engl J Med 2000; 342: 868-74. [CrossRef]

3. Light RW. Pleural diseases. 3rd ed. Philadelphia: Lea \& Febinger; 1990.

4. Henry M, Arnold T, Harvey J. BTS guidelines for the management of spontaneous pnuemothorax. Thorax 2010; 65: 18-31.

5. Baumann $M H$, Strange $C$, Heffner JE, Light R, Kirby TJ, Klein J, et al. Management of spontaneous pneumothorax: an American College of Chest Physicians Delphi consensus statement. Chest 2001; 119: 590-602. [CrossRef]

6. Tintinalli JE, Kelen GD, Stapczynski JS, Ma, OJ, Cline DM, editors. Tintinalli's Emergency Medicine. Spontaneous And latrogenic Pneumothorax 6th ed. New York: McGraw-Hill 2004; 66: 462-5.

7. Bense L, Eklund G, Wiman LG. Smoking and the increased risk of contracting spontaneous pneumothorax. Chest 1987; 92: 1009-12. [CrossRef]

8. Sadikot RT, Greene T, Meadows K, Arnold AG. Recurrence of spontaneous pneumothorax. Thorax 1997; 52: 805. [CrossRef]

9. Kuzucu A, Soysal O, Ulutaş H. Optimal timing for surgical treatment to prevent recurrence of spontaneous pneumothorax. Surg Today 2006; 36 : 865-8. [CrossRef]

10. Gupta D, Mishra S, Faruqi S, Aggarwal AN. Aetiology and clinical profile of spontaneous pneumothorax in adults. Indian J Chest Dis Allied Sci 2006; 48: 261-4.

11. Türkyılmaz A, Erdem AF, Aydın Y, Çinici O, Eroglu A. Treatment of Secondary Spontaneous Pneumothorax: 100-Patient Experience. Eurasian J Med 2007; 39: 97-102.

12. Türker H, Akkaya $E$, Koralp F. Evaluation of patients with spontaneous pneumothorax and its place in the treatment of aspiration. Respiratory 1993; 18: 670-6.

13. Gürbüz L, Altay T. 113 Spontan pnömotorakslı vakanın değerlendiriminden çıkarılan sonuçlar. Tüberküloz Toraks 1976; 24: 52-6.

14. Celik B, Kefeli Celik H, Hamzaçebi H, Demir H, Furtun K, Ortamevzi C. The role of meteorological conditions on the development of spontaneous pneumothorax. Thorac Cardiovasc Surg 2009; 57: 409-12. [CrossRef]

15. Güneylioğlu D, Altınsoy B, Çelik O, Mihmanlı A, Akkaya E. Pnömotoraks: 174 olgunun değerlendirilmesi. Akciğer Arşivi 2002; 2: 78-81.

16. Khan N, Wazir MS, Yasin M, Mohammad J, Javed A. Etiology, Presentation and Management Outcome of Pneumothorax. J Ayub Med Coll Abbottabad 2005; 17: 62-4.

17. Brims FJ, Maskell NA. Ambulatory treatment in the management of pneumothorax: A systematic review of the literature. Thorax 2013; 68: 668-9.

18. Cheng JS, Hsu HH, Tsai KT, Yuan A, Chen WJ, Lee YC. Salvage for unsuccessful aspiration of primary pneumothorax. Ann Thorac Surg 2008; 85: 1908-13. [CrossRef]

19. Çobanoğlu U, Sayır F, Melek M, Mergan D, Selvi F. Yüzyedi spontan pnömotoraks olgusunda klinik deneyimimiz. J Clin Anal Med 2011; 2: 548. [CrossRef]

20. Noppen $M$, Alexander $P$, Driesen $P$, Slabbynck $H$, Verstraeten A. Manual aspiration versus chest tube drainage in first episodes of primary spontaneous pneumothorax: a multicenter, prospective, randomized pilot study. Am J Respir Crit Care Med 2002; 165: 1240-4. [CrossRef]

21. Baumann $M H$, Strange $C$. Treatment of spontaneous pneumothorax: $A$ more aggressive approach? Chest 1997; 112: 789-804.

22. Soulsby T. British Thoracic Society guidelines for the management of spontaneous pneumothorax: do we comply with them and do they work? J Accid Emerg Med 1998; 15: 317-21.

23. Çok G, Karakuş H, Göksel T, Güzelant A, Bayındır Ü. Primer ve sekonder spontan pnömotorakslı olguları karşılaştıran geriye dönük bir çalışma. Toraks Dergisi 2001; 2: 18-21.

24. Dumont P, Diemont F, Massard G, Toumieux B, Wihlm JM, Morand G. Does a thoracoscopic approach for surgical treatment of spontaneous pneumothorax represent progress? Eur J Cardiothorac Surg 1997; 11: 27 31. 
25. Huber-Wagner S, Körner M, Ehrt A, Kay MV, Pfeifer KJ, Mutschler W, et al. Emergency chest tube placement in trauma care - which approach is preferable? Resuscitation 2007; 72: 226-33.

26. Aylwin CJ, Brohi K, Davies GD, Walsh MS. Pre-hospital and in-hospital thoracostomy: indications and complications. Ann R Coll Surg Engl 2008; 90: 54-7. [CrossRef]

27. Kashani P, Harati S, Shirafkan A, Amirbeigi A, Hatamabadi HR. Comparing the Quality and Complications of Tube Thoracostomy by Emergency Medicine and Surgery Residents; a Cohort Study. Emerg (Tehran) 2017; 5: e33.

28. Şentürk E, Bulut A, Türe $M$, Yoldaş E, Doğan Y. Acil tüp torakostomi uygulamalarında morbidite. Turkiye Klinikleri Archives Lung 2011; 12: 1-8.
29. Chee CBE, Abisheganaden J, Yeo JKS, Lee P, Huan PYM, Poh SC, et al. Persistant air-leak in spontaneous pneumothorax - clinical course and outcome. Respir Med 1998; 92: 757-61. [CrossRef]

30. Çelik B, Nadir A, Şahin E, Kaptanoğlu M, Demir H, Furtun K. Nüks spontan pnömotorakslı olgularda risk faktörleri, klinik ve radyolojik değerlendirme. Türk Göğüs Kalp Damar Cer Derg 2008; 16: 107-12.

31. Ball CG, Lord J, Laupland KB, Gmora S, Mulloy RH, Ng AK, et al. Chest tube complications: How well are we training our residents. Can J Surg 2007; 50: $450-8$.

32. Onuki T, Ueda S, Yamaoka M, Sekiya Y, Yamada H, Kawakami N, et al. Primary and Secondary Spontaneous Pneumothorax: Prevalence, Clinical Features, and In-Hospital Mortality. Can Respir J 2017; 2017: 6014967.[CrossRef] 